\title{
Tat peptide-admixed elastic liposomal formulation of hirsutenone for the treatment of atopic dermatitis in $\mathrm{NC} / \mathrm{Nga}$ mice
}

This article was published in the following Dove Press journal:

International Journal of Nanomedicine

19 October 2011

Number of times this article has been viewed

\author{
Myung Joo Kang' \\ Jae Yoon Eum' \\ Mi Sook Jeong ${ }^{2}$ \\ Sang Han Park' \\ Ki Young Moon' \\ Mean Hyung Kang' \\ Min Soo Kim' \\ Sun Eun Choi' \\ Min Won Lee' \\ Do Ik Lee' \\ Hyoweon Bang ${ }^{2}$ \\ Chung Soo Lee ${ }^{2}$ \\ Seong Soo Joo ${ }^{3}$ \\ Kapsok $\mathrm{Li}^{2}$ \\ Mi-Kyung Lee ${ }^{2}$ \\ Seong Jun $\mathrm{Seo}^{2}$ \\ Young Wook Choi' \\ 'College of Pharmacy, Chung- \\ Ang University, Heuksuk-dong, \\ Dongjak-gu,Seoul, ${ }^{2}$ College of Medicine, \\ Chung-Ang University, Heuksuk- \\ dong, Dongjak-gu, Seoul, ${ }^{3}$ Division \\ of Marine Molecular Biotechnology, \\ Gangneung-Wonju National University, \\ Gangneung, South Korea
}

Correspondence: Young Wook Choi College of Pharmacy, Chung-Ang University, 22I Heuksuk-dong,

Dongjak-gu, Seoul 156-756, South Korea

Tel +82 28205609

Fax +82 28263781

Email ywchoi@cau.ac.kr

Seong Jun Seo

College of Medicine, Chung-Ang

University, 22I Heuksuk-dong,

Dongjak-gu, Seoul I56-756, South Korea

Tel +82262991538

Fax +82 28231049

Email drseo@hanafos.com
Background: The aim of the present study was to enhance a topical delivery of hirsutenone (HST), a naturally occuring immunomodulator, employing Tat peptide-admixed elastic liposomes (EL/T).

Methods: HST-loaded EL, consisting of phosphatidylcholine and Tween 80 (85:15 w/w\%), were prepared using thin film hydration method. By adding Tat peptide to EL $(0.16 \mathrm{w} / \mathrm{w} \%)$, EL/T were formulated. The in vitro skin permeation of HST was examined using a Franz diffusion cell mounted with depilated mouse skin. Lesions for atopic dermatitis (AD) were induced by a topical application of diphenylcyclopropenone to NC/Nga mice. Therapeutic improvements of $\mathrm{AD}$ were evaluated by clinical skin severity scores. Immunological analyses on inducible nitric oxide synthase and cyclooxygenase-2 levels in the skin and interleukin (IL)-4, IL-13, immunoglobulin E, and eosinophil levels in the blood were also performed.

Results: EL systems were superior to conventional cream, revealing greater flux values in a permeation study. The addition of Tat peptide further increased the skin permeation of HST. In an efficacy study with AD-induced NC/Nga mice, an HST-containing EL/T formulation brought a significant improvement in both skin severity score and immune-related responses for the levels of nitric oxide synthase, cyclooxygenase-2, IL-4, IL-13, immunoglobulin E, and eosinophils.

Conclusion: A novel EL/T formulation was successfully developed for topical delivery of HST to treat AD.

Keywords: hirsutenone, elastic liposomes, atopic dermatitis, NC/Nga mice, Tat peptide

\section{Introduction}

Patients with atopic dermatitis (AD), a chronically relapsing inflammatory skin disease, suffer from allergic symptoms such as redness, flaking, and itching. ${ }^{1}$ The causes of $\mathrm{AD}$ are not completely understood, but complex inflammatory immune dysregulation and susceptible responses to environmental allergens are believed to be involved. ${ }^{2}$ $\mathrm{AD}$ is characterized by type 2 helper $\mathrm{T}$ cell ( $\mathrm{Th} 2$ )-dominated immunity that leads to elevated levels of serum immunoglobulin E (IgE) and peripheral eosinophils. ${ }^{2,3}$ It is also indicated by increased inflammatory enzymes including inducible nitric oxide synthase (iNOS) and cyclooxygenase-2 (COX-2) in the skin. Topical corticosteroids as immunosuppressors have been used for over 50 years as first-line therapy for AD, but their side effects, including skin atrophy and striae, are major obstacles for longterm application. ${ }^{4}$ Alternatively, many potential compounds originating from natural sources such as olive oil, omega oils, royal jelly, and magnolol have been widely investigated to develop a natural remedy for AD. ${ }^{5-8}$

Hirsutenone (HST), 1,7-bis-(3,4-dihydroxyphenyl)-4-heptene-3-one, is one of the major diarylheptanoids isolated from the bark of Alnus japonica ${ }^{9}$ Hirsutenone inhibits 
12-O-tetradecanoylphorbol-13-acetate (TPA)-induced COX-2 expression and the synthesis of prostaglandin $\mathrm{E}_{2}$ in human mammary epithelial MCF $10 \mathrm{~A}$ cell lines. ${ }^{10} \mathrm{~A}$ recent study revealed that HST reduced the production of cytokine mRNAs such as interleukin (IL)-2, 4, 5, 13, and interferon- $\gamma$ after T-cell receptor stimulation and, remarkably, suppressed the degranulation of mast cells, indicating the feasibility of HST as a new topical drug candidate for AD therapy. ${ }^{11}$ By virtue of its lipophilic nature, HST could be actively translocated into cells. However, because of the water-insoluble properties of HST, solubilization and incorporation of the drug are necessary for topical formulation development. In addition, a penetration-enhancing system is required to achieve therapeutic concentrations to deeper skin layers of the epidermis and/or dermis.

Several methods to enhance skin delivery have been explored by employing chemical enhancers, creams, vesicular carriers, ultrasound aids, and the use of microneedles. ${ }^{12-14}$ It was found that elastic liposomes (EL), a phospholipid vesicular system containing edge activators, were very effective in enhancing the dermal and/or transdermal deliveries of both lipophilic and hydrophilic molecules. Compared with the conventional liposomes, EL are able to respond to an external stress by rapid shape transformation and can penetrate the skin efficiently in terms of quantity and depth. ${ }^{15,16}$ Researchers have proposed that these liposomal vesicles could improve the skin delivery of drugs by one of the following mechanisms: intact vesicular skin penetration, a penetration enhancing effect, or penetration of liposomes through the transappendageal route. ${ }^{17,18}$ Another pharmaceutical approach to enhance skin delivery is to employ cell-penetrating peptides. Some experiments have demonstrated that cell-penetrating peptides including YARA, WLR, R9, and Tat (Trans-activating transcriptional activator) peptides were useful not only for intracellular delivery but also for promoting the skin penetration of molecules in mice. ${ }^{19,20} \mathrm{~A}$ recent study showed that Tat peptide facilitates the translocation of drugs into immune cells in the skin. ${ }^{21}$

Therefore, a novel Tat peptide-admixed EL (EL/T) containing HST was developed. The in vitro skin permeation properties and in vivo therapeutic efficacy of this formulation were then compared with other formulations of either the cream type or an EL system. Therapeutic improvements of $\mathrm{AD}$ in NC/Nga mice were evaluated by clinical skin severity scores. The immunological analyses of suppression levels for iNOS, COX-2, IL-4, IL-13, IgE, and eosinophil were also conducted.

\section{Materials and methods}

\section{Animals}

Male 5-week-old ICR mice and female 5-week-old NC/Nga mice were purchased from Orient Bio (Kyungki-Do, Korea) and Charles River (Yokohama, Japan), respectively. They were maintained for 2 weeks before the start of the experiments and were housed in an air-conditioned animal room with a 12-hour light-dark cycle (08:00-20:00 hours light, 20:00-08:00 hours dark) at a controlled temperature of $23^{\circ} \mathrm{C} \pm 2{ }^{\circ} \mathrm{C}$ and humidity of $50 \% \pm 10 \%$. Mice were provided with a laboratory diet and water ad libitum. All animal experiments were performed in accordance with the National Institutes of Health (NIH) Principles of Laboratory Animal Care guidelines (NIH publication No. 85-23, revised 1996) and were approved by the Institutional Animal Care and Use Committee of Chung-Ang University in Seoul, South Korea.

\section{Chemicals and reagents}

Hirsutenone (purity $>95 \%$ by high-performance liquid chromatography [HPLC]) was provided from Chung-Ang University Pharmacognosy Laboratory (Seoul, South Korea). Soybean phosphatidylcholine (PC), cholesterol, Tween 80 , phosphate-buffered saline (PBS) tablets, butylated hydroxytoluene (BHT), and N,N-diethylnicotinamide (DENA) were purchased from Sigma Aldrich (St Louis, MO). Tat peptide (Arg-Lys-Lys-Arg-Arg-Gln-Arg-Arg-Arg, 9 mer) was synthesized from Peptron Co (Taejun, South Korea). Polyglyceryl-3-methylglucose distearate, stearic acid, cetyl alcohol, mineral oil, and glycerin used for cream preparation were kindly provided by LG Life Science Ltd (Seoul, South Korea). Sodium carboxymethylcellulose was purchased from Duksan Pure Chemical Co (Kyungkido, South Korea). All other chemicals and reagents were purchased from commercial sources and were of analytical grade. Doubly distilled water was used for all experiments.

\section{Preparation of topical formulations Preparation of EL formulations}

HST-loaded EL were prepared using a previously published thin-film hydration method. ${ }^{22}$ Briefly, PC and Tween 80 $(85: 15 \mathrm{w} / \mathrm{w} \%)$ were dissolved in chloroform and methanol (1:1) in a round-bottom flask. After dissolving HST, the organic solvent was removed by rotary vacuum evaporation above the lipid transition temperature and solvent traces were removed under nitrogen gas. The lipid film was then hydrated with distilled water containing an antioxidant (BHT $0.005 \mathrm{w} / \mathrm{v} \%$ ) to prevent drug oxidation and 
then sonicated in a bath sonicator (model 2210, Branson Ultrasonics Co, Danbury, CT) for 20 minutes. Tat-admixed EL (EL/T) were formulated by adding Tat peptide to EL at a concentration of $0.16(\mathrm{w} / \mathrm{w} \%)$, equivalent to the peptide to lipid molar ratio of $0.1: 100$. The final lipid concentration in all vesicular formulations was $13 \mathrm{mg} / \mathrm{mL}$, and the drug concentration was $1.0 \mathrm{w} / \mathrm{w} \%$. A thickening agent, sodium carboxymethylcellulose, was added to both EL formulations at a concentration of $0.5 \mathrm{w} / \mathrm{w} \%$ to improve the application of formulations to the postaxial back of the mouse.

\section{Preparation of cream formulations}

A conventional oil-in-water type cream (CC) containing $1.0 \mathrm{w} / \mathrm{w} \%$ HST was prepared as follows. Water-insoluble HST was dissolved in an oil phase consisting of mineral oil (7\%), stearic acid (5\%), cetyl alcohol (2\%), and BHT (0.005\%), with polyglyceryl-3-methylglucose distearate $(3 \%)$ used as an emulsifier. The aqueous phase consisted of glycerin (10\%) and distilled water. The oil phase was added to the aqueous phase and then homogenized for 10 minutes, degassed, and cooled under vacuum. Tat-admixed conventional cream $(\mathrm{CC} / \mathrm{T})$ was prepared by mixing Tat peptide into $\mathrm{CC}$ at a concentration of $0.16 \mathrm{w} / \mathrm{w} \%$ and rehomogenizing for 3 minutes. Both cream formulations were then stored for about 24 hours before subjected to evaluation.

\section{Physical characterization of EL formulations}

\section{Size and zeta potential}

Liposomal vesicles were diluted with an appropriate volume of water and were examined for size distribution and zeta potential using a dynamic light scattering particle size analyzer (Zetasizer Nano-ZS; Malvern Instruments, Worcestershire, UK) with a $50 \mathrm{mV}$ laser at a scattering angle of $90^{\circ}$. All measurements were carried out under ambient conditions and in triplicate.

\section{Loading efficiency}

Unencapsulated drug was separated from the liposomes by centrifugation at $15,000 \mathrm{rpm}$ for 10 minutes. ${ }^{23}$ The supernatant was analyzed for HST by HPLC. The entrapment efficiency of the liposomes was calculated by $[(\mathrm{T}-\mathrm{C}) / \mathrm{T}] \times 100$, where $\mathrm{T}$ is the total amount of drug initially added, and $\mathrm{C}$ is the amount of drug detected in the supernatant. ${ }^{24}$

\section{Elasticity of the vesicle membrane}

The vesicle suspension was driven through a microporous filter by an external pressure of 2.5 bars. $^{25}$ The size of the vesicles was monitored using dynamic light scattering measurement before and after filtration. The elasticities of the vesicle membranes were calculated using the previously reported formula: $D=J \times\left(r_{v} / r_{p}\right),{ }^{2}$ where $D$ is the deformability index of the vesicle membrane, $J$ is the amount of vesicle suspension extruded for $5 \mathrm{~min}, r_{v}$ is the size of the vesicle after extrusion, and $r_{p}$ is the pore size of the barrier. ${ }^{26}$

\section{In vitro skin permeation study \\ Solubilization of HST for sink conditions}

To maintain the sink conditions in the receptor compartment for HST, DENA was selected as a hydrotropic agent for solubilization of the hydrophobic drug. ${ }^{27}$ An excess amount of HST was added to PBS containing various concentrations of DENA and then vortexed. The mixture was shaken intermittently at ambient temperature for 24 hours to reach equilibrium. The supersaturated sample was centrifuged at $12,000 \mathrm{rpm}$ for 10 minutes to separate the undissolved HST. The supernatant was then filtered through a $0.45 \mu \mathrm{m}$ membrane filter (Whatman, Piscataway, NJ) and diluted with methanol for the HST assay by HPLC.

\section{Skin permeation of HST}

An in vitro permeation study was conducted with vertical Franz diffusion cells as previously described. ${ }^{18,28}$ Skin tissues were obtained from hairy ICR mice, from whom the dorsal hair of the mouse skin was carefully removed using electric clippers and rinsed with phosphate buffer. A circular piece of dorsal skin was then carefully mounted onto the receiver compartment of the diffusion cells with the stratum corneum facing toward the donor compartment. The receptor compartment was filled with $10 \mathrm{mM}$ PBS ( $\mathrm{pH} 7.4$ ) solution containing 1.5 M DENA and was maintained at $32^{\circ} \mathrm{C}$. Each formulation containing the equivalent amount of HST $(5.0 \mathrm{mg})$ was applied to the skin surface, which had an available diffusion area of $1.76 \mathrm{~cm}^{2}$. The aliquots $(0.5 \mathrm{~mL})$ were withdrawn at predetermined time intervals and analyzed by HPLC. The cumulative amount of drug permeated per unit area was plotted as a function of time. The steady-state permeation rate $\left(J_{\text {ss }}\right)$ and lag time ( $\mathrm{T}_{\mathrm{L}}$, hours) were calculated from the slope and $\mathrm{X}$-intercept of the linear portion, respectively.

\section{HST assay by HPLC}

The quantitative determination of HST was performed by HPLC using acetonitrile- $0.3 \%$ acetic acid in water (25:75) as a mobile phase at a flow rate of $1 \mathrm{~mL} /$ minute. The HPLC system consisted of a pump (L-2130), a UV detector (L-2400), a data station (LaChrom Elite, Hitachi, Japan), 
and a $15 \mathrm{~cm} \mathrm{C}_{18}$ column (Shiseido, Tokyo, Japan). The column eluant was monitored at $220 \mathrm{~nm}$, and the HST peak was separated at a retention time of 12.0 minutes.

\section{In vivo efficacy and immune-related responses}

\section{Induction of AD in mice and the topical application of HST}

AD-like lesions were induced by a topical application of diphenylcyclopropenone (DPCP), a well-known contact allergen, to NC/Nga mice as previously described. ${ }^{29}$ The mouse skin was stimulated for 10 weeks by $0.1 \%$ DPCP solution under ambient conditions. $\mathrm{AD}$ was characterized by itching, erythema, and hemorrhage, followed by edematous superficial erosion, deep excoriation, scaling, and dryness of the skin. ${ }^{30}$ For topical application, regrown hairs on the postaxial backs of the mice were removed a day before the experiment. The mice were treated daily for 4 weeks with drug-free $\mathrm{CC}$ base alone (control) or drug-containing topical formulations of $\mathrm{CC} / \mathrm{T}$ and $\mathrm{EL} / \mathrm{T}$.

\section{Clinical observation of skin severity}

The clinical severity of dermatitis was assessed in a blinded fashion using a previously described method. ${ }^{8,29} \mathrm{~A}$ total score for skin severity was defined as the sum of the individual scores, graded as 0 (no lesion), 1 (mild lesion), 2 (moderate lesion), and 3 (severe lesion), for each sign and symptom, such as erythema, edema, oozing or crust, excoriation, lichenification, and dryness.

\section{Measurement of iNOS and COX-2 levels in skin}

Mice were sacrificed at 4 weeks after HST treatment. An area of approximately $1.5 \times 1.5 \mathrm{~cm}^{2}$ was excised, and the subcutaneous fat and blood vessels were carefully dissected away. Expression levels of iNOS and COX-2 in the skin were measured by Western blotting. ${ }^{31}$ Skin tissues were lysed in a buffer containing $50 \mathrm{mM}$ tris(hydroxymethyl)amino methane, $150 \mathrm{mM}$ sodium chloride, $0.02 \%$ sodium azide, $100 \mu \mathrm{g} /$ $\mathrm{mL}$ phenylmethanesulfonyl fluoride, $1 \%$ Triton X100, and $1 \mu \mathrm{g} / \mathrm{mL}$ aprotinin. After centrifugation, the supernatant was loaded onto a $15 \%$ sodium dodecyl sulfate polyacrylamide gel and electrophoresed. For iNOS and COX-2 detections, the electrophoretically resolved proteins were transferred onto nitrocellulose membranes (Osmonics, Milwaukee, WI). The membrane was incubated with anti-iNOS and COX-2 polyclonal antibodies (1:1000 in 5\% bovine serum albumin [Chemicon, Temecula, CA]) and then washed three times with a Triton X100-containing PBS solution. Relative protein levels were measured using scanning densitometry of the band intensities in the immunoblots after visualization of protein with an enhanced chemiluminescence detection kit (ECL Advance Western Blotting Detection Kit; Amersham Pharmacia Biotech, UK).

\section{Measurement of IL-4, IL- I3, IgE, and eosinophil} levels in blood

The amounts of IL-4, IL-13, IgE, and eosinophil in treated mouse blood were quantified according to a previously described method. ${ }^{32}$ Blood was collected from the retroorbital plexus of mice under ether anesthesia. Serum was obtained by centrifugation of whole blood at $12,000 \mathrm{rpm}$ and was stored at $-20^{\circ} \mathrm{C}$ until use. The levels of IL-4 and IL-13 were measured using a mouse IL-4 ELISA kit and a mouse IL-13 ELISA kit (R\&D Systems, Minneapolis, $M N)$. The amount of total IgE in the serum was determined using a mouse IgE ELISA kit. An eosinophil count was conducted on $30 \mu \mathrm{L}$ of capillary blood diluted sixfold with saline. Microscopic differential counts were performed on Wright-Giemsa-stained blood smears. Eosinophil counts were calculated from the differential counts.

\section{Statistical analysis}

All data are expressed as mean \pm standard deviation. Statistical significance was checked by $t$-test and was considered to be significant at $P<0.05$, unless otherwise indicated.

\section{Results and discussion Characteristics of topical formulations}

EL formulations were characterized by vesicular size, zeta potential, loading efficiency, and deformability index. Vesicular size was measured on average at $130-150 \mathrm{~nm}$, which is considered as an ideal size for skin delivery. ${ }^{33}$ Surface charges in the EL were measured at about $-30 \mathrm{mV}$ but were neutralized by the addition of Tat peptide to about $-10 \mathrm{mV}$ due to electrostatic adhesion of the cationic peptide to the vesicular surface. EL formulations showed a high loading efficiency of HST over $70 \%$. HST was efficiently encapsulated into the liposome due to its lipophilicity. In comparison, liposomal encapsulation of oregonin, a hydrophilic diarylheptanoid as a glycoside form, has been shown to be markedly lower than that of HST. ${ }^{34}$ The deformability index of EL, a crucial feature of elastic liposomes for skin penetration enhancement, was observed at about 60 , which is a three- to fourfold greater value than that of conventional liposomes. ${ }^{14,34}$ The incorporation of an edge activator, Tween 80 , destabilized the lipid bilayers, thereby increasing the deformability of the vesicles. ${ }^{35}$ The stress-dependent adaptability of EL imparts an exclusive 
ability to pass through the skin barrier with ease, which in turn provides an adjuvant effect for HST permeation. Conventional oil-in-water type cream formulations were prepared successfully and appeared as white, opaque, homogeneous semifluids with no bleeding or phase separation. HST was solubilized in the oil phase, and no drug crystals were observed. Under the presence of the antioxidant BHT $(0.005 \%)$, the drug contents in all formulations were maintained at over $98 \%$ during the experimental period.

\section{Sink conditions for skin permeation study}

Although physiological saline was potentially the most appropriate receptor phase, an appropriate solubilizing agent was required to provide a sufficient solubility for HST and to maintain the sink conditions during the permeation studies. The aqueous solubility of HST was increased by several orders of magnitude in the presence of DENA, a novel hydrotropic agent (Figure 1). The increased solubilization might be attributed to the complexation of DENA with the drug molecule, alterations in the nature of water as a solvent, and self-associations in aqueous solution at high concentration of the hydrotropic agent $(>1 \mathrm{M}) .{ }^{36,37}$ In particular, a medium with $1.5 \mathrm{M}$ DENA provided about $6 \mathrm{mg} / \mathrm{mL}$ of HST solubility. This equilibrium solubility guarantees the sink conditions for HST, because the total amount of HST in the donor phase was $5 \mathrm{mg}$, and the volume of the receptor phase was $11 \mathrm{~mL}$ in the Franz diffusion cell.

\section{Skin permeation profiles of HST}

The in vitro permeation profiles of HST in various topical formulations, including CC, CC/T, EL, and EL/T, are shown in Figure 2. Permeation of HST in conventional creams was

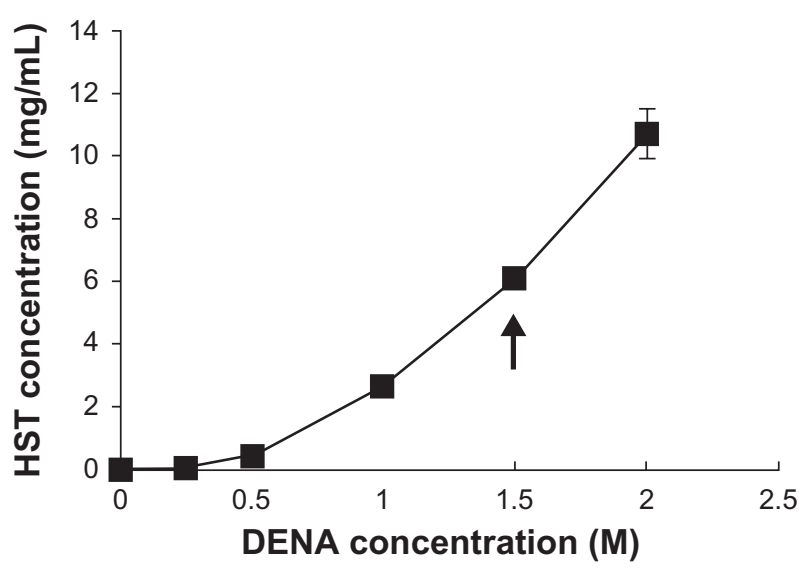

Figure I Solubilities of HST in DENA solutions at $20^{\circ} \mathrm{C}$. Arrow indicates a sufficient solubility of HST to maintain the sink conditions in the receptor phase of the skin permeation study.

Note: Values represent mean \pm standard deviation, $\mathrm{n}=3 .^{34}$

Abbreviations: HST, hirsutenone; DENA, N,N-diethylnicotinamide.

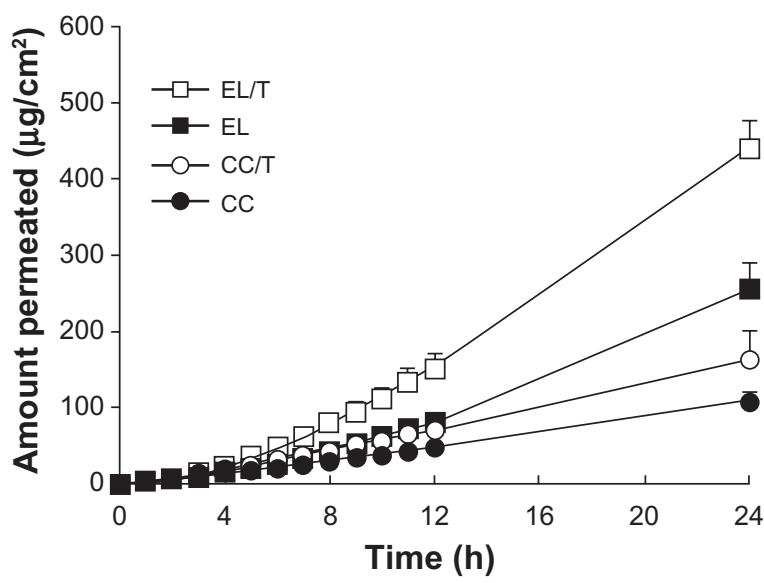

Figure 2 Permeation profiles of HST in various formulations through depilated mouse skin for 24 hours.

Note: Values represent mean \pm standard deviation, $\mathrm{n}=3 .{ }^{34}$

Abbreviations: $\mathrm{CC}$, conventional cream; CC/T, Tat-admixed conventional cream; EL, elastic liposomes; EL/T, Tat peptide-admixed elastic liposomes.

significantly lower than those of the liposomal formulations. The slope of the EL/T formulation was much steeper than those of the other formulations. The order of HST penetration at 24 hours was as follows: EL/T $>\mathrm{EL}>\mathrm{CC} / \mathrm{T}>\mathrm{CC}$. The skin permeation parameters of HST from liposomal and nonliposomal formulations are summarized in Table 1. Compared with cream formulations, liposomal formulations revealed greater values in flux and cumulative amount permeated at 24 hours. However, incorporation of the drug into liposomes resulted in skin permeation time lag because of the required time for HST-containing liposomal nanovesicles to migrate from the gel matrix of the vehicle. In particular, EL/T formulation significantly increased the amounts of HST permeated (\%): 1.7-fold versusEL, 2.7-fold versus CC/T, and4.1-fold versus CC. It was determined that EL systems were superior to cream formulations and that the addition Tat peptide even further improved topical delivery of HST.

In looking further into the details of flux values for different formulations, formulation effects on the skin permeation of HST for two variables were noticed: EL formulation and

Table I Permeation parameters of HST in various formulations through depilated mouse skin (mean \pm standard deviation, $\mathrm{n}=3$ )

\begin{tabular}{lllll}
\hline & CC & \multicolumn{1}{l}{ CC/T } & \multicolumn{1}{l}{ EL } & \multicolumn{1}{l}{ EL/T } \\
\hline$J_{\text {ss }}\left(\mu g / h / \mathrm{cm}^{2}\right)^{\mathrm{a}}$ & $4.88 \pm 0.49$ & $7.37 \pm 1.55$ & $13.33 \pm 1.69$ & $22.63 \pm 1.62$ \\
Permeated $(\%)^{\mathrm{b}}$ & $3.80 \pm 0.45$ & $5.74 \pm 1.32$ & $8.99 \pm 1.18$ & $15.48 \pm 1.3 \mathrm{I}$ \\
$\mathrm{T}_{\mathrm{L}}(\mathrm{h})^{\mathrm{c}}$ & $2.12 \pm 0.34$ & $2.13 \pm 0.69$ & $4.92 \pm 0.4 \mathrm{I}$ & $4.83 \pm 0.28$ \\
\hline
\end{tabular}

Notes: ${ }^{\text {aFlux }}$ was obtained from the slope of the permeation profile in Figure 2; ${ }^{b}$ Calculated from the cumulative amount permeated at 24 hours divided by the amount of drug loaded into the samples; 'Lag time calculated from the $\mathrm{X}$-intercept of the linear portion.

Abbreviations: $\mathrm{HST}$, hirsutenone; CC, conventional cream; CC/T, Tat-admixed CC; EL, elastic liposomes; EL/T, Tat-admixed EL. 
Tat peptide addition (Figure 3). The enhancement ratio was expressed as a relative ratio of the flux values. EL and EL/T showed enhancement ratios of 2.7 and 3.1 versus $\mathrm{CC}$ and $\mathrm{CC} / \mathrm{T}$, respectively. The high, stress-dependent transformability of EL enabled them to travel between the cells in the stratum corneum, which effectively allows them to pass through the intact skin spontaneously under the influence of the naturally occurring transcutaneous hydration gradient. A previous study has shown that EL rapidly enters the deeper layers of the stratum corneum and can reach layers almost as deep as the stratum corneum-viable epidermal junction. ${ }^{15,38}$ However, the addition of Tat peptide further intensified the skin penetration-enhancing capacity of EL. EL/T exhibited an enhancement ratio of 1.7 versus that of EL, which followed a similar trend to the cream formulations. This result is consistent with an earlier report that stated that the noncovalent WLR fragment, one of the penetrating peptides, was twice as effective in promoting the penetration of macromolecules into the skin. ${ }^{19}$ It is also supported by an earlier report stating that several penetrating peptides are able to interact with lipids in the stratum corneum and enter into a layer of cells via a macropinocytosis mechanism, forming a gradient from the outer to the inner cell layers, thus facilitating the delivery of drug. ${ }^{39}$

\section{In vivo therapeutic efficacy for skin severity}

To evaluate the therapeutic efficiency of HST-loaded EL/T and $\mathrm{CC} / \mathrm{T}$ formulations for $\mathrm{AD}$ severity in vivo, $\mathrm{AD}$-like lesions were artificially induced in NC/Nga mice. Mice with AD-like lesions manifested with severe pruritis,

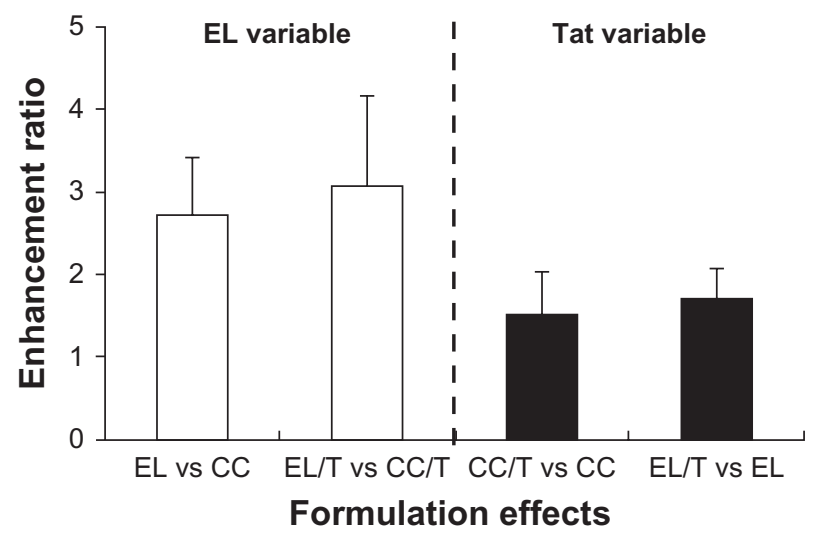

Figure 3 Comparison of formulation effects on skin permeation of HST based on two variables of EL formulation and Tat peptide addition. Enhancement ratio was expressed as a relative ratio of the flux values.

Note: Data are expressed as mean \pm standard deviation, $\mathrm{n}=3 .{ }^{34}$

Abbreviations: CC, conventional cream; EL, elastic liposomes; EL/T, Tat peptide-admixed elastic liposomes; HST, hirsutenone. dryness, and eczema, showing no significant differences in severity level between mice. AD-like lesions on the dorsal skin in the control group presented as a reddish-colored wound and dried skin even after 4 weeks. Compared with the normal group, the HST-treated groups showed considerable reductions in these symptoms, demonstrating complete recovery within 4 weeks following treatment (Figure 4). Evaluation of AD scoring (SCORing Atopic Dermatitis) for skin severity (Figure 5) showed that both $\mathrm{EL} / \mathrm{T}$ and $\mathrm{CC} / \mathrm{T}$ formulations started to show significantly different improvements within a week, and that the values continued to reduce gradually for up to 4 weeks. The EL/T-treated group revealed the best result with complete recovery within 2 weeks following topical application, a significant difference $(P<0.05)$ from that of the $\mathrm{CC} / \mathrm{T}$ treatment. The superiority of the EL/T formulation correlated very well with the in vitro skin permeation results. This trend in formulation differences was maintained for 3 weeks after treatment, even though there was a small decrease in score values. However, at 4 weeks after treatment, there were no significant differences between the EL/T- and CC/T-treated groups. It is therefore concluded that the EL/T formulation brought about a rapid and profound improvement as an AD therapy.

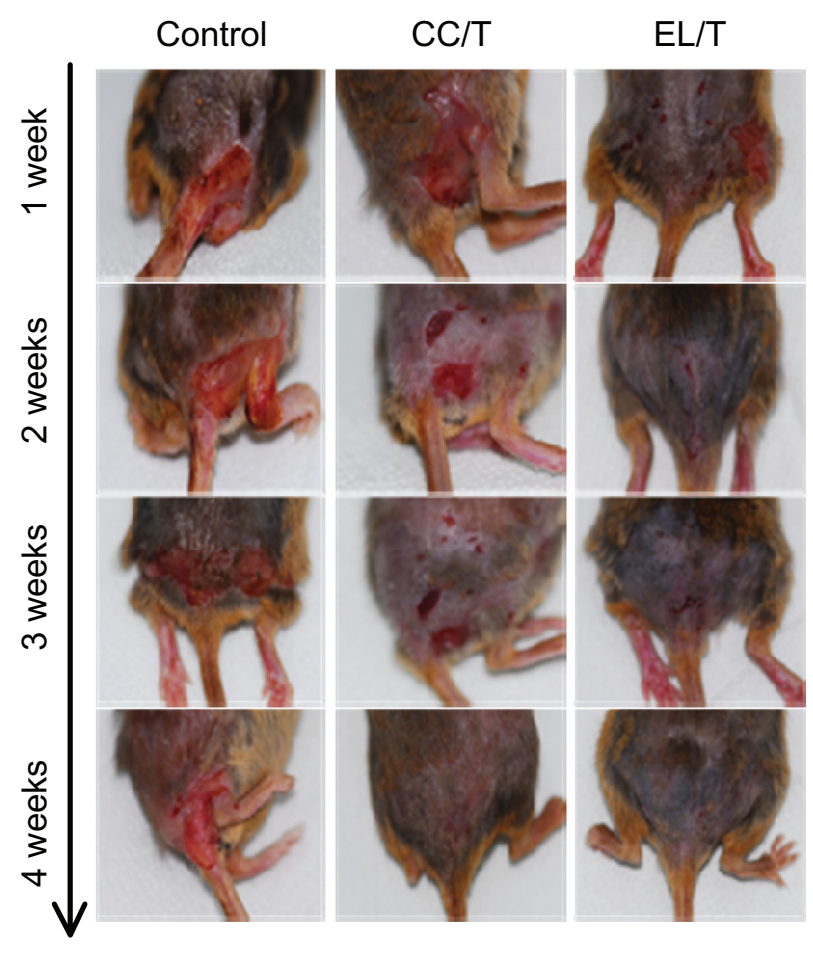

Figure 4 Clinical observations of atopic dermatitis-like skin lesions in NC/Nga mice after topical administration of various formulations: drug-free cream base (control), Tat-admixed conventional cream $(\mathrm{CC} / \mathrm{T})$, and Tat-admixed elastic liposomes $(\mathrm{EL} / \mathrm{T}))^{34}$ 


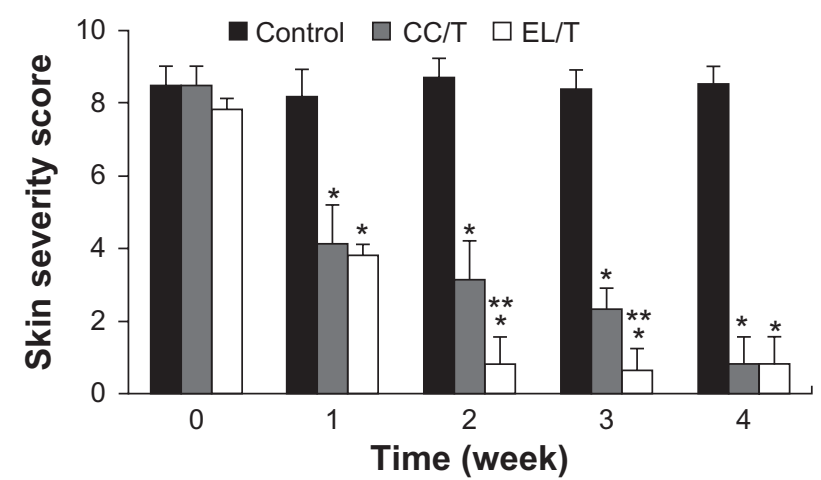

Figure $\mathbf{5}$ Changes in skin severity score after topical application of HST formulations: control, CC/T and EL/T. A total score for skin severity was defined as the sum of the individual scores, graded as 0 (none), I (mild), 2 (moderate), and 3 (severe), for each sign and symptom, such as erythema, edema, oozing or crust, excoriation, lichenification and dryness.

Notes: Bar represents standard deviation $(n=3)$, and the statistical analysis was performed using the $t$-test $(* P<0.05$ versus control; **P $<0.05$ versus $C C / T){ }^{34}$ Abbreviations: $\mathrm{CC} / \mathrm{T}$, Tat-admixed conventional cream; EL/T, Tat peptideadmixed elastic liposomes; HST, hirsutenone.

\section{Suppression of iNOS and COX-2 levels in skin}

Diarylheptanoids including HST have been shown to promote antioxidant effects through scavenging actions on superoxides and 1,1-diphenyl-2-picrylhydrazyl radicals. ${ }^{40}$ These compounds prevent the expressions of iNOS and COX-2 in RAW264.7 macrophages in a dose-dependent manner. ${ }^{10}$ Both HST-treated groups resulted in marked declines in both iNOS and COX-2 expression levels (Figure 6), which were significantly different $(P<0.05)$ from those of the control. Although a more than $50 \%$ reduction in expression levels was obtained using the $\mathrm{CC} / \mathrm{T}$ treatment, the $\mathrm{EL} / \mathrm{T}$ treatment decreased the levels even further to about $30 \%$, revealing significant differences between the two treatment groups. In accordance with the clinical observations of skin severity, the entrapment of the drug in an EL/T system facilitated the transfer of HST to skin and thereby increased the antiinflammatory activity of the drug.

\section{Suppression of IL-4, IL-I 3, IgE and eosinophil levels in blood}

In the present study, repeated treatment with DPCP in $\mathrm{NC} / \mathrm{Nga}$ mice triggered IgE and eosinophil hyperproduction with upregulation of IL-4 and IL-13. All immune response levels were greatly elevated in the control group, in which the elevation remained constant even after 4 weeks of treatment with drug-free cream base (Figure 7). Studies of $\mathrm{NC} / \mathrm{Nga}$ mice with AD symptoms have also demonstrated the elevation of immune responses, including IL-4, IL-13, IgE, and eosinophil levels. ${ }^{41-43}$ The increased serum IgE level
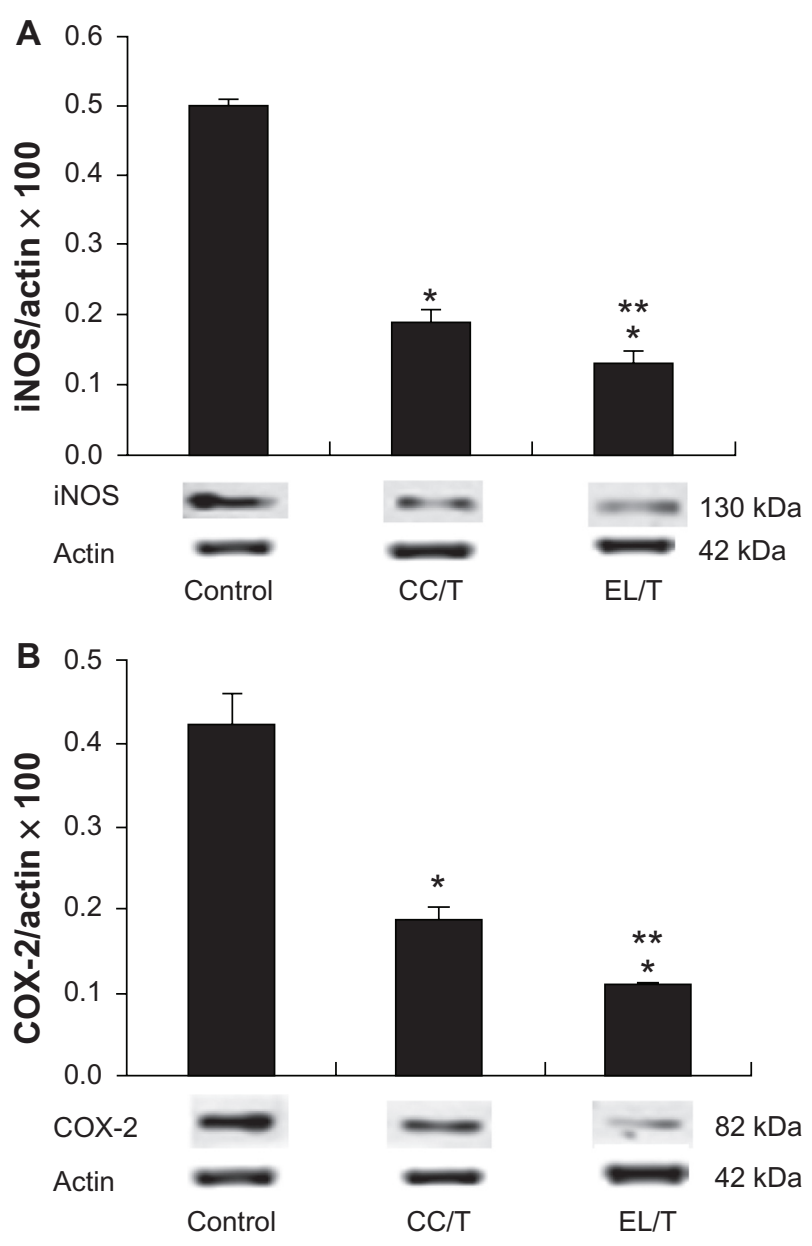

Figure 6 Alterations of (A) iNOS and (B) COX-2 levels in NC/Nga mouse skin after topical application of HST formulations: control, CC/T and EL/T.

Notes: The levels were determined by Western blotting. Bar represents SD $(n=3)$, and the statistical analysis was performed using the $t$ test $(* P<0.05$ versus control; **P $<0.05$ versus $\mathrm{CC} / \mathrm{T}){ }^{34}$

Abbreviations: CC/T, Tat-admixed conventional cream; EL/T, Tat peptideadmixed elastic liposomes; HST, hirsutenone.

would be driven from the Th1/Th2 imbalance skewed to Th2, in which Th2 cytokines such as IL-4 and IL-13 play key roles in the hyperproduction of $\operatorname{IgE} .{ }^{44}$ In addition, leukotrienes generated by eosinophils amplify inflammatory cascades by acting as chemotactic factors or by triggering the release of cytotoxic proteins. ${ }^{45,46}$ Meanwhile, HST treatment with $\mathrm{CC} / \mathrm{T}$ or EL/T formulation brought remarkable and significant reductions in all levels to less than half of that of the control $(P<0.05)$, revealing the effectiveness of HST for AD therapy. However, unexpectedly, there were no significant differences between the two treatment groups in the suppression levels for IL-4, IL-13, $\mathrm{IgE}$, or eosinophils. These results might be due to the fact that expression levels of these parameters were mostly normalized in NC/Nga mice after 4 weeks of HST application regardless of its formulation. 


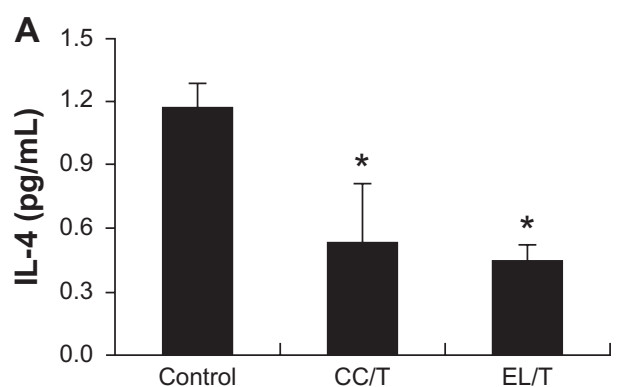

C

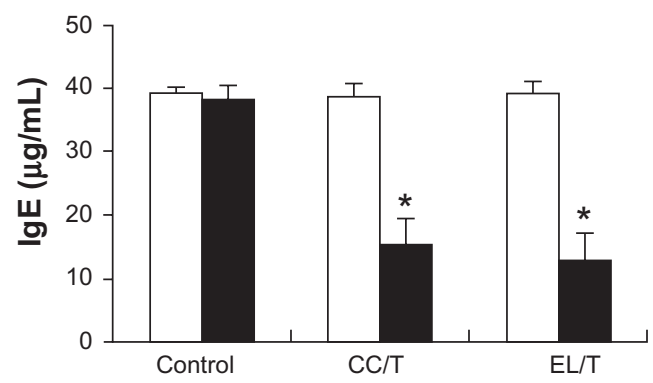

B

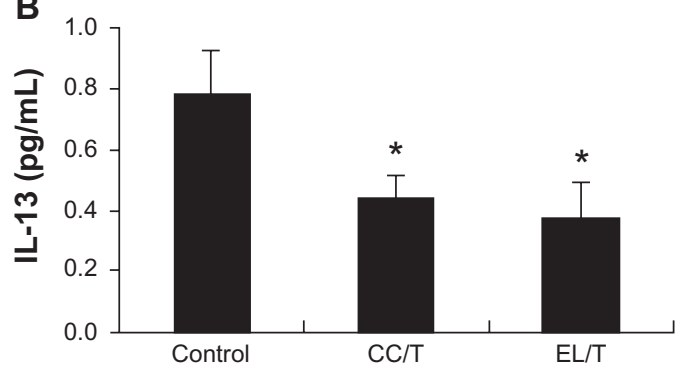

D

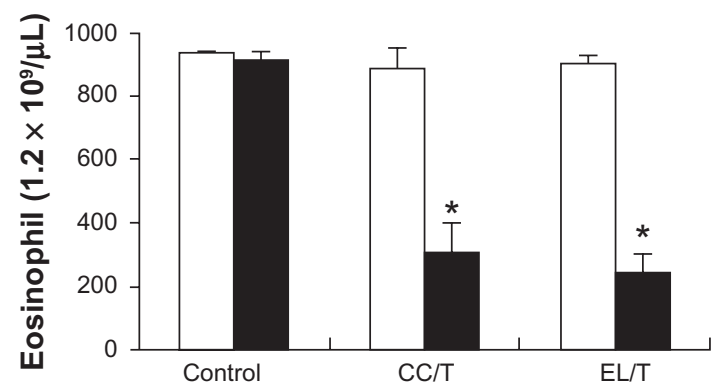

Figure 7 Changes in IL-4, IL-13, IgE and eosinophil levels in NC/Nga mouse blood after topical application of HST formulations: control, CC/T and EL/T. Bar graphs represent the levels before the treatment (empty) and 4 weeks after the treatment (filled). (A) The serum IL-4 levels as measured using an ELISA kit; (B) The serum IL-I 3 levels as measured using an ELISA kit; (C) the serum IgE levels as measured using an ELISA kit; (D) blood eosinophil number as counted by the microscopic differential count.

Note: Bar represents standard deviation $(\mathrm{n}=3)$, and the statistical analysis was performed using the $t$ test $\left(* P<0.05\right.$ versus control). ${ }^{34}$

Abbreviations: CC/T, Tat-admixed conventional cream; EL/T, Tat peptide-admixed elastic liposomes; HST, hirsutenone.

\section{Conclusion}

A major obstacle to achieving therapeutic effectiveness is delivery of the pharmacologically active agent to its site of action. The results of this study show that elastic liposomal formulations can be advantageous for the topical delivery of HST, a naturally occurring lipophilic immunomodulator, in in vitro skin permeation and in vivo therapeutic efficacy. Therefore, the HST-loaded EL/T formulation developed in this study can be used to treat $\mathrm{AD}$ as an alternative to steroid therapy, which is very limited for long-term application due to the severe side effects.

\section{Acknowledgment}

This study was supported by a grant from the Korea Healthcare Technology R\&D Project, Ministry for Health, Welfare and Family Affairs, Republic of Korea (A091121).

\section{Disclosure}

The authors have no conflicts of interest to declare in relation to this paper.

\section{References}

1. Leung DY, Bieber T. Atopic dermatitis. Lancet. 2003;361(9352): 151-160.

2. Akdis AC, Akdis M, Trautmann A, Blaser K. Immune regulation in atopic dermatitis. Curr Opin Immunol. 2002;12(6):641-646.
3. Leung DY. Atopic dermatitis: the skin as a window into the pathogenesis of chronic allergic disease. J Allergy Clin Immunol. 1995;96(3): 302-318.

4. Thaci D. Long term management of childhood atopic dermatitis with calcineurin inhibitors. Hautarz. 2003;54(5):418-423.

5. Noori SA. Topical application of natural honey, beeswax and olive oil mixture for atopic dermatitis or psoriasis: partially controlled, singleblinded study. Complement Ther Med. 2003;11(4):226-234.

6. Taniguchi Y, Kohno K, Inoue S, et al. Oral administration of royal jelly inhibits the development of atopic dermatitis-like skin lesions in NC/Nga mice. Int Immunopharmacol. 2003;3(9):1313-1324.

7. Mainardi T, Kapoor S, Bielory L. Complementary and alternative medicine: herbs, phytochemicals and vitamins and their immunologic effects. J Allergy Clin Immunol. 2009;123(2):283-294.

8. Choi SE, Jeong MS, Kang MJ, et al. Effect of topical application and intraperitoneal injection of oregonin on atopic dermatitis in $\mathrm{NC} / \mathrm{Nga}$ mice. Exp Dermatol. 2010;19(8):e37-e43.

9. Asakawa Y. Chemical constituents of Alnus firma (Betulaceae). Bull Chem Soc Japan. 1970;43(7):2223-2229.

10. Kim JH, Lee KW, Lee MW, Lee HJ, Kim SH, Surh YJ. Hirsutenone inhibits phorbol ester-induced upregulation of COX-2 and MMP-9 in cultured human epithelial cells: NFkB as a potential molecular target. FEBS Letters. 2006;580(2):385-392.

11. Joo SS, Kim SG, Choi SE, et al. Suppression of T cell activation by hirsutenone, isolated from the bark of Alnus japonica, and its therapeutic advantages for atopic dermatitis. Eur J Pharmacol. 2009; 614(1-3):98-105.

12. Trotta M, Peira E, Debernardi F, Gallarate M. Elastic liposomes for skin delivery of dipotassium glycyrrhizinate. Int J Pharm. 2002;241(2): 319-327.

13. Paliwal S, Mitragotri S. Ultrasound-induced cavitation: applications in drug and gene delivery. Expert Opin Drug Deliv. 2006;3(6):713-726.

14. Prausnitz MR. Microneedles for transdermal drug delivery. Adv Drug Deliv Rev. 2004;56(5):581-587. 
15. Dubey V, Mishra D, Asthana A, Jain NK. Transdermal delivery of a pineal hormone: melatonin via elastic liposomes. Biomaterials. 2006;27(18);3491-3496.

16. Kim YM, Kim BG, Kang MJ, Eum JY, Choi YW. In vivo skin deposition and photoprotection effect of genistein in liposomal gel formulations. J Kor Pharm Sci. 2009;38(5):325-329.

17. Bouwstra JA, Honeywell-Nguyen PL. Skin structure and mode of action of vesicles. Adv Drug Deliv Rev. 2002;54(1):41-55

18. Cevc G, Blume G. New, highly efficient formulation of diclofenac for the topical, transdermal administration in ultradeformable drug carriers, Transfersomes. Biochim Biophys Acta. 2001;1514(2):191-205.

19. Lopes LB, Furnish E, Komalavilas P, et al. Enhanced skin penetration of P20 phosphopeptide using protein transduction domains. Eur J Pharm Biopharm. 2008;68(2):441-445.

20. Hou YW, Chan MH, Hsu HR, et al. Transdermal delivery of proteins mediated by non-covalently associated arginine-rich intracellular delivery peptides. Exp Dermatol. 2007;16(12):999-1006.

21. Rothbard JB, Garlington S, Lin Q, et al. Conjugation of arginine oligomers to cyclosporin A facilitates topical delivery and inhibition of inflammation. Nat Med. 2000;6(11):1253-1257.

22. Nagarsenker MS, Londhe VY, Nadkarmi GD. Preparation and evaluation of liposomal formulations of tropicamide for ocular delivery. Int J Pharm. 1999;190(1):63-71.

23. Mohammed AR, Weston N, Coombes AGA, Fitzgerald M, Perrie Y. Liposome formulation of poorly water soluble drugs: optimization of drug loading and ESEM analysis of stability. Int J Pharm. 2004;285(1-2):23-34.

24. Touitou E, Davan N, Bergelson L, Godin B, Eliaz M. Ethosomes novel vesicular carriers for enhanced delivery: characterization and skin penetration properties. J Control Release. 2000;65(3):403-418.

25. Cevc G, Gebauer D, Stieber J, Schatzlein A, Blume G. Ultraflexible vesicles, transfersomes, have an extremely low pore penetration resistance and transport therapeutic amount of insulin across the intact mammalian skin. Biochim Biophys Acta. 1998;1368(2):201-215.

26. Bergh BAI, Wertz PW, Junginger HE, Bouwstra JA. Elasticity of vesicles assessed by electron spin resonance, electron microscopy and extrusion measurements. Int J Pharm. 2001;217(1-2):13-24.

27. Lee J, Lee SC, Acharya G, Chang CJ, Park J. Hydrotropic solubilization of paclitaxel: Analysis of chemical structures for hydrotropic property. Pharm Res. 2003;20(7):1022-1030.

28. Huailiang W, Ramachandran C, Weiner ND, Roessier BJ. Topical transport of hydrophilic compounds using water-in-oil nanoemulsions. Int J Pharm. 2001;220(1-2):63-75.

29. Taniguchi $\mathrm{Y}$, Kohno $\mathrm{K}$, Inoue $\mathrm{S}$, et al. Oral administration of royal jelly inhibits the development of atopic dermatitis-like skin lesions in NC/Nga mice. Int Immunopharmacol. 2003;3:1313-1124.

30. Vestergaard C, Yoneiyama H, Murai M, et al. Overproduction of Th2specific chemokines in NC/Nga mice exhibiting atopic dermatitis-like lesions. J Clin Invest. 1999;104(8):1097-1105.
31. Singh RP, Gu M, Aqarwal R. Silibinin inhibits colorectal cancer growth by inhibiting tumor cell proliferation and angiogenesis. Cancer Res. 2008;68(6):2043-2050.

32. Kim YS, Kim Y, Lee KJ, Kwon HJ, Kim DS, Kim TY. Improvement of atopic dermatitis in NC/Nga mice by topical application of $\mathrm{CpG}$ hosphodiester-ODN. Int Arch Allergy Immunol. 2007;144(4):315-324.

33. Verma DD, Verma S, Blume G, Fahr A. Particle size of liposomes influences dermal delivery of substances into skin. Int J Pharm. 2003;258(1-2):141-151.

34. Kang MJ, Eum JY, Jeong MS, et al. Facilitated skin permeation of oregonin by elastic liposomal formulations and suppression of atopic dermatitis in NC/Nga mice. Biol Pharm Bul. 2010;33(1):100-106.

35. El Maghraby GM, Williams AC, Barry BW. Oestradiol skin delivery from ultradeformable liposomes: renement of surfactant concentration. Int J Pharm. 2000;196(1):63-74.

36. Coffman RE, Kildsig DO. Hydrotropic solubilization mechanistic studies. Pharm Res. 1996;13(10):1460-1463.

37. Charman WN, Lai CSC, Finnin BC, Reed BL. Self-association of nicotinamide in aqueous solution: mass transport, freezing-point depression, and partition coefficient studies. Pharm Res. 1991;8(9):1144-1150.

38. Honeywell-Nguyen PL, Gooris GS, Bouwstra JA. Quantitative assessment of the transport of elastic and rigid vesicle components and a model drug from these vesicle formulations into human skin in vivo. $J$ Invest Dermatol. 2004;123(5):902-910.

39. Lopes LB, Brophy CM, Furnish E, et al. Comparative study of the skin penetration of protein transduction domains and a conjugated peptide. Pharm Res. 2005;22(5):750-757.

40. Kuroyanagi M, Shimomae M, Nagashima Y, et al. New diarylheptanoids from Alnus japonica and their antioxidative activity. Chem Pharm Bull. 2005;53(12):1519-1523.

41. Matsuda H, Watanabe N, Geba GP, et al. Development of atopic dermatitis-like skin lesion with IgE hyperproduction in NC/Nga mice. Int Immunol. 1997;9(3):461-466.

42. Gao XK, Fuseda K, Shibata T, Tanaka H, Inagaki N, Nagai H. Kampo medicines for mite antigen-induced allergic dermatitis in NC/Nga mice. Evid Based Complement Alternat Med. 2005;2(2):191-199.

43. Tohru S, Kogiso M, Mituya K, Komatsu T, Yamamoto S. Genistein suppresses development of spontaneous atopic-like dermatitis in $\mathrm{NC} / \mathrm{Nga}$ mice. J Nutr Sci Vitaminol. 2006;52(4):293-296.

44. Kotani M, Matsumoto M, Fujita A, et al. Persimmon leaf extract and astragalin inhibit development of dermatitis and $\operatorname{IgE}$ elevation in NC/Nga mice. J Allergy Clin Immunol. 2000;106(1):159-166.

45. Lewis RA, Austen KF, Soberman RJ. Leukotrienes and other products of the 5-lipoxygenase pathway. Biochemistry and relation to pathobiology in human disease. $N$ Engl J Med. 1990;323(10):645-655.

46. Shaw RJ, Walsh GM, Cromwell O, Mogbell R, Spry CJ, Kay AB. Activated human eosinophils generate SRS-A leukotrienes following IgG-dependent stimulation. Nature. 1985;316(6024):150-152.
International Journal of Nanomedicine

\section{Publish your work in this journal}

The International Journal of Nanomedicine is an international, peerreviewed journal focusing on the application of nanotechnology in diagnostics, therapeutics, and drug delivery systems throughout the biomedical field. This journal is indexed on PubMed Central,

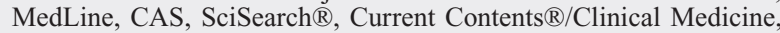

\section{Dovepress}

Journal Citation Reports/Science Edition, EMBase, Scopus and the Elsevier Bibliographic databases. The manuscript management system is completely online and includes a very quick and fair peer-review system, which is all easy to use. Visit http://www.dovepress.com/ testimonials.php to read real quotes from published authors. 